\title{
1 The evolution of social life in family groups
}

2 Jos Kramer $^{1 *}$ and Joël Meunier ${ }^{2}$

$3{ }^{1}$ Department of Plant and Microbial Biology, University of Zürich, Zürich, Switzerland

$4{ }^{2}$ Institut de Recherche sur la Biologie de l'Insecte (IRBI), UMR 7261, CNRS, University of Tours,

5 France

$6 \quad *$ Corresponding author: J. Kramer; JosKramer@gmx.de | +41 446352902

7 Orcid-IDs: J Kramer: orcid.org/0000-0003-2155-9295

8

J Meunier: orcid.org/0000-0001-6893-2064

$9 \quad 13156$ words | 1 figure 


\section{ABSTRACT}

Family life forms an integral part of the life-history of species across the animal kingdom, and plays a crucial role in the evolution of animal sociality. Our current understanding of family life, however, is almost exclusively based on studies that (i) focus on parental care and associated family interactions (such as those arising from sibling rivalry and parent-offspring conflict), and (ii) investigate these phenomena in the advanced family systems of mammals, birds, and eusocial insects. Here, we argue that these historical biases have fostered the neglect of key processes shaping social life in ancestral family systems, and thus profoundly hamper our understanding of the (early) evolution of family life. Based on a comprehensive survey of the literature, we first illustrate that the strong focus on parental care in advanced social systems has deflected scrutiny of other important social processes such as sibling cooperation, parent-offspring competition and offspring assistance. We then show that accounting for these neglected processes - and their evolutionary origin and subsequent consolidation of family life. Finally, we outline how this diachronic perspective on the evolution of family living could provide novel insights into general processes driving social evolution. Overall, we infer that the explicit consideration of thus far neglected facets of family life, together with their study across the whole diversity of family systems, are crucial to advance our understanding of the processes that shape the evolution of 28 social life. sociality; precocial; altricial; parent-offspring conflict; sibling rivalry 


\section{CONTENT}

32 I. INTRODUCTION

33 II. THE SEMANTICS OF FAMILY LIFE

34 III. THE NEGLECTED FACETS OF FAMILY LIFE

(1) SibLing COOPERATION

(2) PARENT-OfFSPRING COMPETITION

(3) OFFSPRING ASSISTANCE

(1) THE EMERGENCE OF FAMILY LIFE

(a) The standard account: the evolution of post-hatching parental care

(2) THE CONSOLIDATION OF FAMILY LIFE 


\section{INTRODUCTION}

54 Social life in family groups is a highly variable phenomenon that occurs widespread across the

55 animal kingdom. Family groups can not only be found in vertebrates such as mammals, birds and

56 (non-avian) reptiles, but also in numerous invertebrates including arthropods, molluscs and

57 annelids (Clutton-Brock, 1991; Trumbo, 2012; Wong, Meunier, \& Kölliker, 2013). Both within

58 and across these taxa, families can vary tremendously in terms of composition, persistence and

59 intimacy of social interactions (Klug, Alonso, \& Bonsall, 2012; Trumbo, 2012). For instance,

60 family groups can be composed of offspring and either their mother, their father, or both parents;

61 they can last from only few hours to an entire lifetime; and they can range from temporary and

62 facultative aggregations over cooperatively breeding groups to highly integrated eusocial

63 societies featuring reproductive division of labour (Hölldobler \& Wilson, 1990; Costa, 2006;

64 Koenig \& Dickinson, 2016).

The emergence of family life is commonly thought to constitute a transition from solitary

66 to social life, and marks the initial step in the major evolutionary transition to eusociality

67 (Maynard Smith \& Szathmáry, 1995; Bourke, 2011). This is because the origin of family life

entails the emergence of a novel - social - environment (cf. Badyaev \& Uller, 2009; Uller, 2012)

69 that can not only become an integral part of an organism's life-history (Clutton-Brock, 1991;

70 Gross \& Clutton-Brock, 2005; Wong et al., 2013), but may also create long-lasting bonds

71 between parents and their offspring. Such bonds preceded the evolution of many derived social

72 behaviours (Darwin, 1871; Wilson, 1975; Royle, Smiseth, \& Kölliker, 2012a), and thus likely

73 drove the transformation of simple family systems to advanced animal societies. Eusocial

74 societies, for instance, likely arose from family units in which offspring delayed dispersal and 
75 independent reproduction, and instead assisted their parents in raising younger siblings

76 (Boomsma \& Gawne, 2017). Studying family life can thus help elucidating factors that shape the

77 evolution of complex animal societies (e.g. Wheeler, 1928; Michener, 1969; Wilson, 1975;

78 Bourke, 2011), and more generally shed light on mechanisms that commonly promote the emergence and maintenance of social life in nature.

Despite its crucial role in social evolution, the origin and maintenance of family life is somewhat surprisingly often only touched upon indirectly in studies focusing on parental care

82 (but see, for instance, (Falk et al., 2014; Jarrett et al., 2017). Parental care comprises a variety of traits ranging from gamete provisioning over nest construction to brood attendance and food provisioning (reviewed in Clutton-Brock, 1991; Costa, 2006; Smiseth, Kölliker, \& Royle, 2012;

85 Wong et al., 2013), and generally encompasses "any parental trait that enhances the fitness of a parent's offspring, and that is likely to have originated and/or to be currently maintained for this function" (Smiseth et al., 2012). The expression of parental care often has a large impact on the fitness of both parents and offspring. In particular, parental care is beneficial to offspring, because it increases their quality and/or survival by neutralizing environmental hazards (AlonsoAlvarez \& Velando, 2012; Klug \& Bonsall, 2014). By contrast, parental care is often costly to parents, because it reduces their condition and/or survival (for instance as the result of an

92 increased energy loss or elevated risk of predation), and thus ultimately diminishes their lifetime reproductive success (Trivers, 1972; Alonso-Alvarez \& Velando, 2012). The far-reaching consequences associated with the expression of parental care make it the core feature of family

95 life. Shedding light onto the circumstances that allow family members to gain sufficient (indirect) benefits to offset the costs of care (cf. Hamilton, 1964; Smiseth et al., 2012) has thus long been 
97 considered central in the study of social life in family groups (Clutton-Brock, 1991; Gross \&

98

99

100

101

102

103

104

105

106

107

108

109

110

111

112

113

114

115

116 117 Moreover, the central role of parental care arguably deflects scrutiny of fitness effects that are

Clutton-Brock, 2005).

However, parental care is but one of many facets of family life, and only a fraction of the other facets has received close scrutiny thus far. For instance, it is well known that the expression of care can prompt evolutionary conflicts (cf. Parker, Royle, \& Hartley, 2002; Royle, Hartley, \& Parker, 2004) that become apparent (i) if one parent tries to reduce its parental investment at the other parent's expense (parental antagonism; Trivers, 1972; Lessells, 2012; Parker et al., 2015); (ii) if offspring compete with each other for limited parental resources (sibling rivalry; Mock \& Parker, 1997; Roulin \& Dreiss, 2012); and (iii) if offspring demand more care than the parents are willing to provide (parent-offspring conflict; Trivers, 1974; Kilner \& Hinde, 2012; Kölliker et al., 2015). By contrast, processes such as sibling cooperation and parent-offspring competition only recently started to attract attention (e.g. Dreiss, Lahlah, \& Roulin, 2010; Yip \& Rayor, 2013; Falk et al., 2014; Schrader, Jarrett, \& Kilner, 2015a; Kramer et al., 2017). This disparity arguably results from a strong bias toward studying family interactions in the derived social systems of birds and mammals. In these groups, young offspring are completely dependent on parental resources, and the substantial fitness effects of parental care that parallel this dependency typically prompt intense conflicts over the allocation of care (Clutton-Brock, 1991;

Gross \& Clutton-Brock, 2005). Derived family systems, however, only represent a small fraction of the diversity of family life in nature. Their predominance in studies of family interactions thus promotes the neglect of mechanisms that could play a greater role in less derived family systems. typically masked by the benefits and costs of (conflicts over the allocation of) parental care. The 
strong focus on parental care and its expression in altricial species hence likely distorts our understanding of the evolutionary drivers of the emergence and consolidation of family life, and could ultimately obscure their role in the (early) evolution of animal sociality.

Here, we advocate the direct study of family life as an integrative approach to elucidating the role of parental behaviours and other family interactions in the evolution of animal sociality.

To this end, we (i) illustrate the downsides of a narrow focus on parental care by reviewing how thus far neglected types of family interaction can shape the cost-benefit ratio of family life. We then (ii) outline how accounting for these overlooked mechanisms - and their changing role in the course of evolution - could improve our understanding of the evolutionary origin and consolidation of family life. Finally, (iii) we discuss how this diachronic perspective on the evolution of family living could provide general insights into the mechanisms driving social evolution. Understanding the evolution of family life requires a complete picture of all factors that affect its fitness consequences across taxonomical groups. Albeit doubtlessly very important, parental care and its repercussions in advanced family systems only cover part of the canvas.

\section{THE SEMANTICS OF FAMILY LIFE}

Somewhat surprisingly, there is no strict consensus among behavioural ecologists as to what constitutes a family. In studies on cooperative breeding, the term family is typically restricted to cases where mature offspring forgo dispersal and independent reproduction, and instead continue to interact regularly with their parents (Emlen, 1994, 1995; Covas \& Griesser, 2007; Drobniak et al., 2015). This narrow definition helps to identify transitional stages in the evolution of cooperative breeding (a form of family-living characterized by reproductive cooperation; 
140 Drobniak et al., 2015). Yet, this definition also excludes the vast diversity of (less enduring)

141 associations between parents and their immature offspring. A broader meaning of the term

142 "family» is thus frequently implied in studies on parental care (cf. Clutton-Brock, 1991; Gross \&

143 Clutton-Brock, 2005; Schrader et al., 2015b; Duarte et al., 2016; Jarrett et al., 2017). Here, we

144 formalize this view by defining a family as "an association of one or both caring parent(s) with

145 their offspring". This broad definition of the term family closely matches its colloquial meaning,

146 and allows us to outline a general perspective that covers all types of (non-random) parent-

147 offspring association. We suggest using more narrowly define terms such as nuclear family and

148 extended family to delineate families of a particular composition. Specifically, we propose to use

149 the term nuclear family to delineate the vast majority of family systems that consist of one or

150 both caring parent(s) and offspring of a single reproductive attempt. Conversely, we suggest

151 using the term extended family to delineate families consisting of a nuclear family and their close

152 relatives, such that the extended family also comprises grandparents, siblings of the parents,

153 and/or offspring of at least one additional reproductive attempt. Many societies of cooperatively

154 breeding birds, mammals, and eusocial insects are examples of such extended families.

157 captured by the classification into species with altricial and precocial young (from now on referred to as altricial and precocial species, respectively). In altricial species, the phenotypic integration of parental care is advanced to such an extent that juveniles cannot survive without

160 receiving at least some care early during their life. Family life in altricial species is therefore 161 obligatory (Clutton-Brock, 1991). Prime examples of such altricial species are found among 
mammals, passerine birds, and eusocial insects. In precocial species, on the other hand, this

163 phenotypic integration is limited, and offspring can survive in the absence of - nonetheless

164 beneficial - care due to an early development of their capability to forage independently. Family

165 life in precocial species is therefore facultative (Smiseth, Darwell, \& Moore, 2003;

166 Kölliker, 2007). Ducks, plovers, and quails, as well as many subsocial insects (such as burying

167 beetles and earwigs) feature precocial young. Interestingly, the altricial-precocial spectrum

168 broadly coincides with the classification into evolutionarily derived vs. non-derived family

169 systems. In particular, altricial family systems are always derived (and derived systems typically

170 altricial), since the high phenotypic integration of parental care characteristic of such systems

171 only arises after the emergence of family life (section III.3; Kölliker, 2007; Uller, 2012).

172 Conversely, precocial species are typically less derived (and non-derived systems are always

173 precocial), since they feature a lower degree of phenotypic integration, and thus more closely

174 resemble an ancestral state during which offspring were (still) largely independent of parental

175 care (Smiseth et al., 2003; Kölliker, 2007). We are aware that these dichotomic classifications

176 only draw a rough picture of the diversity of family systems. We nevertheless retain them here,

177 because their generality makes them useful in our discussion of the general trends shaping the

178 evolution of family life. 


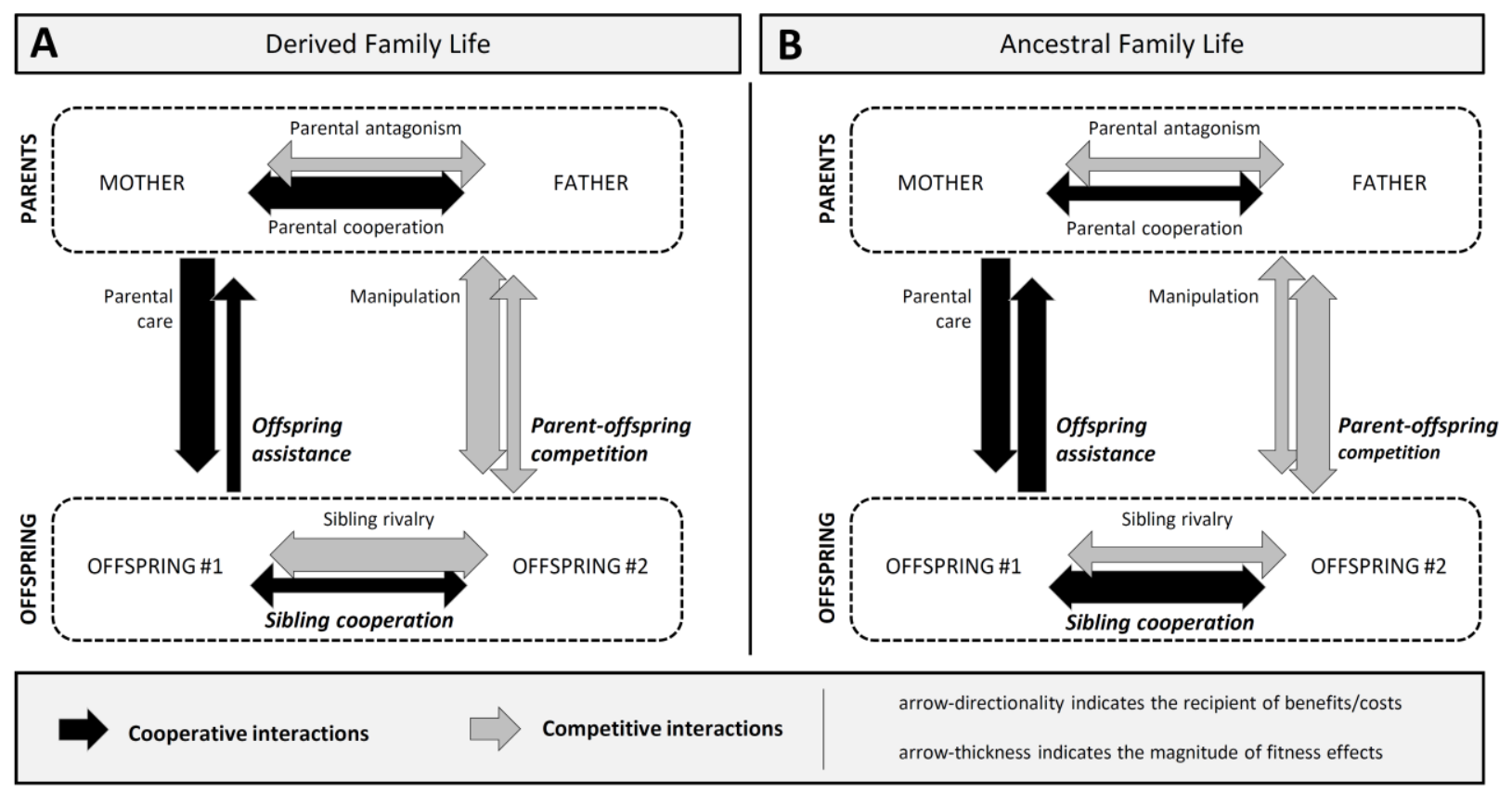

Figure 1 | Social interactions during family life. Depicted are cooperative and competitive interactions (represented, respectively, by black and grey arrows) that can potentially occur among family members in (A) derived and (B) ancestral family systems. Research on family interactions has traditionally focused on altricial vertebrates and eusocial insects, and typically investigated the expression and fitness effects of parental care and the conflicts over (and cooperation in) its allocation. While this strong focus is understandable in the light of the often substantial fitness effects of these phenomena (indicated by the thickness of the corresponding arrows) in derived family systems, it has inadvertently fostered the neglect of other facets of family life (in bold italic print). However, these neglected facets might have played a crucial role in shaping ancestral forms of family life. Notably, the social dynamics in ancestral family systems might be very similar to the dynamics in the extended families of many cooperative breeders. 


\section{THE NEGLECTED FACETS OF FAMILY LIFE}

193

194

IV.2). Below, we review examples of the neglected facets of family life, and highlight that their

207

Family living is a form of group living. The various fitness effects inherent to all types of groupliving - such as the costs of increased competition and the benefits of cooperative foraging should therefore also occur during family life (Alexander 1974; Krause and Ruxton 2002). However, instead of investigating the full range of possible cooperative and competitive family interactions, the last decades of research on family life predominantly focused on the fitness effects of a single type of parent-offspring cooperation - parental care-as well as on the conflicts over (and the cooperation in) its allocation (see Figure 1; reviewed in Clutton-Brock, 1991; Royle, Smiseth, \& Kölliker, 2012b). This implicit equalization of the fitness effects of parental care with the fitness effects of family life has led to the neglect of three potentially important dimensions of social interactions within the family: (i) sibling cooperation, (ii) parent-offspring competition, and (iii) offspring assistance (here defined as cooperative acts of offspring to the benefit of their parents). A notable exception to this general trend are studies on the highly derived, extended families of cooperative breeders, in which these mechanisms have been explored (but see section fitness effects are often concealed by the relatively greater effects of parental care. Accounting for the effects of these mechanisms is nevertheless crucial, since they could augment or diminish the benefits and costs of parental care, and thus tip the scales in favour (or in disfavour) of the emergence and consolidation of family life. 


\section{1 (1) Sibling cooperation}

212 Most studies of sibling interactions thus far investigated the conspicuous competitive behaviours

213 of juvenile birds and mammals that compete over their access to limited parental resources

214 (reviewed in Mock \& Parker, 1997; Roulin \& Dreiss, 2012). However, sibling interactions are not

215 competitive by default, and an increasing number of studies report an unexpected diversity of

216 cooperative interactions (or by-product mutualism) among altricial as well as precocial juveniles

217 (reviewed in Roulin \& Dreiss, 2012). Indeed, sibling cooperation is not only a hallmark of termite

218 societies, where larvae, nymphs, workers and soldiers are all juveniles (Eggleton, 2011), but also

219 occurs in the house wren Troglodytes aedon, where offspring postpone fledging to the benefit of

220 their younger siblings (Bowers, Sakaluk, \& Thompson, 2013); in the King Penguin Aptenodytes

221 patagonicus, where huddling improves the juveniles' thermoregulation (Barré, 1984); in the

222 spotted hyaena Crocuta crocuta, where offspring form coalitions with litter-mates against

223 unrelated juveniles (Smale et al., 1995); and in the Mississippi kite Ictinia mississippiensis and

224 the ambrosia beetle Xyleborinus saxesenii, where offspring express mutual cleaning ('allo-

225 preening'; Botelho, Gennaro, \& Arrowood, 1993; Biedermann \& Taborsky, 2011).

Intriguingly, juveniles can also cooperate in resource acquisition. In altricial species, such

227 cooperation typically aims at improving the juveniles' access to parental provisioning (cf.

228 Forbes, 2007). For instance, altricial juveniles sometimes refrain from interfering with their

229 siblings' feeding attempts (e.g. in the blue-footed booby Sula nebouxii; Anderson \&

230 Ricklefs, 1995) and may even offer parentally-provided food items to their siblings (e.g. in the

231 barn owl Tyto alba; Marti, 1989). Moreover, they can coordinate their begging behaviour to

232 increase the parents' feeding rate (e.g. in the in the black-headed gull Larus ridibundus and the 
233 banded mongoose Mungos mungo; Johnstone, 2004; Mathevon \& Charrier, 2004; Bell, 2007),

234 or negotiate their share of parental resources to avoid the greater costs of unrestrained sibling

235 rivalry (e.g. in the barn owl T. alba, the spotless starling Sturnus unicolor and the meerkat Suricata

236 suricatta; Roulin, 2002; Johnstone \& Roulin, 2003; Bulmer, Celis, \& Gil, 2008; Madden et

237 al., 2009; Dreiss et al., 2010). By contrast, cooperation in resource acquisition among precocial

238 juveniles can - at least in principle - occur independently of parental provisioning. For instance,

239 food sharing occurs even without parental involvement in the European earwig Forficula

240 auricularia (Falk et al., 2014; Kramer, Thesing, \& Meunier, 2015) and in many social spiders such

241 as the huntsman spider Delena cancerides (Yip \& Rayor, 2013, 2014).

In both altricial and precocial species, the fitness effects of sibling cooperation might

243 often be concealed by the effects of parental care. In line with this assumption, it has recently

244 been shown that larval mass in the burying beetle Nicrophorus vespilloides peaks at a higher

245 larval density in the absence of care. This suggests that parental care usually masks the beneficial

246 effect of initial increases in larval density on the brood's ability to penetrate and use the breeding

247 carcass (Schrader et al., 2015a). This notwithstanding, the diverse forms and broad taxonomical

248 distribution of cooperative behaviours among juveniles suggest that sibling cooperation is not

249 only important during the adult life stage (cf. Wilson, 1971; Clutton-Brock, 1991; Koenig \&

250 Dickinson, 2004), but might also play a crucial role in the evolution of family life (see section III).

\section{1 (2) Parent-offspring competition}

252 Competition between parents and their offspring occurs whenever the consumption of an 253 essential resource by the parents limits the availability of this resource to their offspring - or vice 
254 versa. This form of kin competition typically arises with the onset of offspring foraging, and has

255 been predicted to promote offspring dispersal and thus the breakup of family units (Hamilton \&

256 May, 1977; Comins, Hamilton, \& May, 1980; West, Pen, \& Griffin, 2002). Direct evidence for

257 these effects in altricial species is as yet scarce. However, experimental food removal in the

258 western bluebird Sialia mexicana reduced the number of sons that remained with their parents

259 until after winter, suggesting that parent-offspring competition can indeed promote the breakup

260 of family units (Dickinson \& McGowan, 2005). Similarly, food supplementation delayed offspring

261 dispersal in the carrion crow Corvus corone corone, indicating that parent-offspring competition

262 could select against the evolution of cooperative breeding (Baglione et al., 2006). In further

263 support of this notion, resource depletion during the breeding season likely leads to competition

264 between breeders and helpers in the chestnut-crowned babbler Pomatostomus ruficeps, and

265 thus overall increases the costs of group-living (Sorato, Griffith, \& Russell, 2016).

In analogy to its effects in altricial species, parent-offspring competition can also affect

267 offspring dispersal and the duration of family life in precocial species. For instance, parent-

268 offspring competition has been shown to promote offspring dispersal in the solitary common

269 lizard Lacerta vivipara (Léna et al., 1998; Le Galliard, Ferrière, \& Clobert, 2003; Cote, Clobert, \&

270 Fitze, 2007). Conversely, the prolonged presence of fathers has been shown to reduce offspring

271 survival under food limitation in $N$. vespilloides, a burying beetle with biparental care in which

272 both parents feed on the breeding carcass (Scott \& Gladstein 1993; Boncoraglio \& Kilner 2012).

273 This latter finding suggests that father-offspring competition might offset the benefits of paternal

274 care, and thus offers a potential explanation as to why fathers typically leave the brood earlier

275 than mothers in this species. Intriguingly, parent-offspring competition in precocial species might 
even entirely negate the benefits of family living under certain harsh conditions. In line with this

277 hypothesis, mother-offspring competition under food limitation has been shown to render

278 maternal presence detrimental to offspring survival in uniparental families of the European

279 earwig F. auricularia (Meunier \& Kölliker, 2012; Kramer et al., 2017).

Particularly in precocial species, such costs of parent-offspring competition are likely

287 in altricial species, since the benefits of parental care often decrease towards the end of family

288 life (cf. Bateson, 1994), and will thus often be limited once parent-offspring competition arises.

289 Given its early onset and multifaceted role in precocial species, parent-offspring competition 290 might play a crucial role in the evolution of family life (see section III).

\section{1 (3) Offspring assistance}

292 Cooperation between parents and their offspring is prominently featured in a plethora of studies on parental care (reviewed in Clutton-Brock, 1991; Royle et al., 2012b). However, parent- 
297 their parents in raising younger siblings (Wilson, 1971; Bourke \& Franks, 1995; Cockburn, 1998;

298 Koenig \& Dickinson, 2016). Yet offspring assistance during family life can also be performed by

299 juveniles. Among altricial species, it frequently occurs in eusocial insects where larvae/nymphs

300 can fulfil crucial roles for colony functioning (reviewed in Eggleton, 2011; Schultner, Oettler, \&

301 Helanterä, 2017), for instance by defending the colony - and thus the reproductives - as soldiers

302 (in virtually all termites; (Howard \& Thorne, 2011); by taking over gallery extension and the

303 compressing of waste into compact balls (in the ambrosia beetle $X$. saxesenii; Biedermann \&

304 Taborsky, 2011); or by acting as "communal stomach" (cf. Wheeler, 1918; Dussutour \&

305 Simpson, 2009) that provisions the queen with secretions necessary for protein degradation (in

306 the metricus paper wasp Polistes metricus; Hunt, 1984) or sustained egg production (in pharaoh

307 ant Monomorium pharaonis; Børgesen, 1989; Børgesen \& Jensen, 1995).

Apart from its role in altricial species with highly complex societal organization, the notion

of offspring assistance has received little attention. However, recent findings indicate that

310 parents can also benefit from offspring assistance in precocial species. For instance, parents

311 might benefit from their offspring's investment into shared immune traits (social immunity;

312 Cremer, Armitage, \& Schmid-Hempel, 2007; Meunier, 2015), independent foraging, or defence

313 against predation (Krause \& Ruxton, 2002). In line with the former notion, faeces of caring

314 mothers exhibit a lower antifungal activity than those of non-caring females in the European

315 earwig $F$. auricularia, suggesting that mothers might downregulate or at least not compensate

316 for the reduction in their own investment into nest sanitation during family life, and instead rely

317 on the superior antifungal properties of the faeces of their juveniles (Diehl et al., 2015).

318 Conversely, delayed juvenile dispersal improves the survival of tending mothers in the subsocial 
spider Anelosimus studiosus (Jones \& Parker, 2002), a finding that might reflect benefits of offspring investment into prey capture or into the maintenance of the communal web. Indeed, offspring assist in web construction in many social spiders (Yip \& Rayor, 2014), suggesting that mothers could regularly benefit by reducing their own investment. Although such benefits of offspring assistance for parents might be concealed by the costs of parental care, they could nevertheless have a significant impact on the evolution of family interactions and, more generally, on the emergence of social life in family units (see section III). Investigating the role of offspring assistance and the other neglected facets of family life is thus crucial to advance our understanding of the evolution of social life in family groups.

\section{THE (EARLY) EVOLUTION OF FAMILY LIFE}

The evolution of family life generally presumes that the fitness benefits of family living outweigh the costs of a prolonged association of the family members (Alexander, 1974; Clutton-Brock, 1991; Klug et al., 2012). However, the impact of the processes mediating these benefits can change over evolutionary time (Smiseth et al., 2003; Falk et al., 2014; Royle, Alonzo, \& Moore, 2016). This is because the current benefits associated with a trait (such as a parental behaviour) do not necessarily reflect the adaptive value of this trait in an ancestral state (Williams, 1966). For instance, the high benefits associated with parental food provisioning in derived family systems typically reflect the dependency of offspring on food provided by the parents, a state that only evolved after the emergence of parental provisioning. The benefits of parental provisioning are thus likely less pronounced in non-derived family systems (Smiseth et al., 2003; Klug et al., 2012; Royle et al., 2012a). Conversely, mechanisms playing a limited role 
340 in derived systems might have a more prominent role in less derived systems (section III.2.b).

341 Understanding the evolution of family living therefore requires a complete picture of the

342 mechanisms promoting family life in both derived and non-derived family systems.

However, instead of investigating the full range of mechanisms across different family

344 systems, the last decades of empirical research mostly focused on investigating the current

345 benefits and costs of parental care in the derived family systems of altricial vertebrates (reviewed

346 in Clutton-Brock, 1991; Royle et al., 2012b). By contrast, the fitness effects of family interactions

347 in precocial species, which feature facultative forms of family life reminiscent of an ancestral

348 state, have received comparably little attention (but see, for instance, Eggert, Reinking, \&

349 Müller, 1998; Zink, 2003; Salomon, Schneider, \& Lubin, 2005; Kölliker, 2007). Similarly,

350 theoretical approaches have thus far only indirectly explored the evolution of family life, since

351 they typically investigated the influence of life-history characteristics, co-evolutionary dynamics,

352 or environmental conditions on the evolutionary origin and maintenance of parental care

353 (Wilson, 1975; Tallamy, 1984; Tallamy \& Wood, 1986; Bonsall \& Klug, 2011a; Klug et al., 2012).

354 As a corollary of this narrow focus on parental care, our current understanding of the early

355 evolution of family life remains fragmentary. In the following section, we address this

356 fundamental issue. Specifically, we review the factors promoting the emergence and subsequent

357 consolidation of family life, and demonstrate that integrating the costs and benefits of thus far

358 overlooked facets of family life in particular - and the study of precocial family systems in general

359 - could entail major changes in our understanding of the evolution of family life. 


\section{(1) The emergence of family life}

361

362

\section{(a) The standard account: the evolution of post-hatching parental care}

The evolutionary emergence of family life has typically been explored indirectly in studies endeavouring to understand which factors favoured the extension of pre-hatching parental care beyond the time of offspring emergence (e.g. Lack 1968; Clutton-Brock 1991; Smiseth et al. 2012). These studies suggest that the emergence of parental care - and thus family life - requires the concurrence of factors that jointly make sustained social interactions among family members possible and - should the occasion arise - able to spread in the population (Klug et al., 2012). The initial step in the emergence of family life is promoted by life-history characteristics ensuring that social behaviours are primarily directed toward family members (Tallamy \& Wood, 1986; Lion \& van Baalen, 2007). This propensity to mainly interact with family members increases the scope for the evolution of cooperative behaviours (such as parental care and sibling cooperation) by reducing the likelihood that such behaviours are misdirected toward non-kin (Hamilton, 1964; Lion \& van Baalen, 2007). Hence, family life is most likely to emerge if parents and offspring recognize each other (e.g. by means of kin or familiarity recognition; cf. Evans 1998; Fellowes 1998; Dobler and Kölliker 2011) or if they frequently encounter each other (e.g. due to limited dispersal; Hamilton 1964a; Lion and van Baalen 2007). Additionally, the emergence of family life can be promoted by the presence of precursors of post-hatching care (Tallamy \& Wood, 1986; Royle et al., 2012a). In line with this idea, the evolution of offspring attendance and guarding in cooperative breeders has been suggested to derive from ancestral defensive or aggressive behaviours (Tallamy, 1984). Similarly, parental provisioning during family life might have evolved via selection acting on - and modifying - self-feeding behaviours (Cunningham et al., 2016), and 
382

383

384

385

386

387

388

389

390

391

392

393

394

395

396

397

398

399

400

401

402

403

some effector molecules in social immunity might have been recruited from a function in personal immunity (Palmer et al., 2016).

Once the preconditions for the emergence of family life are met, effects of (additional) life-history characteristics and environmental conditions jointly determine whether it can spread in the population against the background of the prevalent solitary lifestyle (Tallamy, 1984; Clutton-Brock, 1991; Klug et al., 2012). In particular, environmental conditions - including the spatial and temporal availability of limited resources and the presence of predators or parasites (reviewed in Wilson, 1975; Krause \& Ruxton, 2002; Botterill-James et al., 2016; see also Botterill-James et al., 2016) - typically modify the impact of basic life-history conditions (such as stage-specific mortality and maturation rates) on the benefits and costs of family interactions (Bonsall \& Klug, 2011a; Klug et al., 2012). For instance, harsh conditions and the concomitant intense competition for limited resources have been predicted to increase the mortality rate of solitary individuals (Wilson, 1975; Clutton-Brock, 1991). This, in turn, should promote the evolution of parental care and thus family life, because the uncertain prospects of future reproduction decrease the relative costs of care to adults (Klug \& Bonsall, 2010; Bonsall \& Klug, 2011a), and increase its potential benefits to offspring (Webb et al., 2002; Klug \& Bonsall, 2010). However, empirical findings are sometimes at odds with these predictions. For instance, harsh conditions negate rather than increase the usual benefits of maternal presence and thus family life in the European earwig F. auricularia (Meunier \& Kölliker, 2012; Kramer et al., 2017). The limited predictive power of the standard account of the evolution of family life (cf. Costa, 2006; Trumbo, 2012; Capodeanu-Nägler et al., 2016) might partly reflect that environmental conditions, life-history characteristics, and the benefits and costs of parental care 
404

405

406

407

408

409

410

411

412

413

414

415

416

417

often interact in unexpected ways (Bonsall \& Klug, 2011a, 2011b; Meunier \& Kölliker, 2012).

However, we believe that it also reflects an excessive focus on a subset of family interactions, and their expression in a subset of family systems.

\section{(b) An extended account: the role of the neglected facets of family life}

The standard account for the evolutionary origin of family life solely focuses on the extension of parental care beyond offspring emergence, and thus inadvertently neglects the role of other social interactions within the nascent family. However, these neglected facets could have a profound influence on family life. In particular, parent-offspring competition (and its potential knock-on effects on sibling rivalry and parental antagonism) could impede the evolution of family life by reducing the potential benefits of care (Meunier \& Kölliker, 2012; Kramer et al., 2017). Conversely, both sibling cooperation and offspring assistance could promote the emergence of family living by, respectively, augmenting the (initially limited) benefits of care to offspring, and offsetting some of its costs to parents (cf. Falk et al., 2014; Kramer et al., 2015). For instance, sibling cooperation during foraging could promote reciprocal food sharing (such as in the vampire bat Desmodus rotundus; Wilkinson, 1984; Carter \& Wilkinson, 2013), and thus provide a mechanism for insurance against variability (Koenig \& Walters, 2015). Intriguingly, these forms of cooperation could themselves evolve from by-product benefits (such as predator dilution effects; Krause \& Ruxton, 2002) arising in offspring aggregations.

The benefits of by-product mutualism or sibling cooperation in such offspring aggregations could also affect the initial duration of family life. In particular, they could offer an additional incentive (or even an alternative reason; see section IV.1) for offspring to delay 
425 dispersal from their natal site (Kramer et al., 2015), and might thus allow extended periods of

426 family life right from the start. This scenario contrast with the standard account for the evolution

427 of family life, where the "simple" extension of parental care beyond offspring emergence (cf.

428 Michener, 1969; Costa, 2006) should initially only allow for brief periods of family life. This is

429 because the standard account neglects the potential impact of cooperation among offspring, and

430 thus implies that offspring in recently evolved family systems should (still) tend to disperse soon

431 after hatching to avoid the impending competition with their siblings and parents (West et

432 al., 2001, 2002). Longer periods of family-living would only arise secondarily, where the benefits

433 of offspring attendance and other early forms of parental care select for delayed offspring

434 dispersal. From an offspring's point of view, family life is classically thought to evolve despite of

435 the presence of competing siblings (cf. Mock \& Parker, 1997; Roulin \& Dreiss, 2012). However,

436 the occurrence and potential role of sibling cooperation suggests that family life might rather

437 emerge - or at least be initially favoured - because of the presence of siblings.

439 of other facets of family life likely depends on life-history characteristics and the prevailing

440 environmental conditions. Costs of parent-offspring competition, for instance, will be greatest if

441 parents and offspring feed on the same resources, and simultaneously forage in the same area.

442 Conversely, the benefits of sibling cooperation might be greatest if offspring forage

443 independently of each other, since this would decrease sibling rivalry (cf. Mock \& Parker, 1997),

444 and thus increase the incentive of juveniles to cooperate with each other (Frank, 1998, 2003).

445 Finally, the possible spectrum of different types of sibling cooperation and offspring assistance is

446 likely subject to developmental constraints (cf. Maynard Smith et al., 1985), where certain types 
447 of behaviours cannot be performed effectively by immatures. Besides these life-history traits, the

448 (environmentally determined) availability of limited resources is likely a crucial factor shaping the

449 fitness effects of the neglected facets of family life. This is because resource limitation would

450 both increase the scope for parent-offspring competition, and decrease the propensity of

451 juveniles to cooperate with their siblings or parents (West et al., 2002; Frank, 2003; see also

452 section III.2.b). Such harsh conditions might thus hamper the evolution of family life despite the

453 expected high benefits of parental care (Webb et al., 2002; Klug \& Bonsall, 2010). Overall, such

454 as yet poorly explored effects might help explaining why even closely related species exposed to

455 ostensibly identical conditions often differ in the occurrence and nature of family interactions (cf.

456 Costa, 2006; Trumbo, 2012; Capodeanu-Nägler et al., 2016).

\section{7 (2) The consolidation of family life}

(a) The standard account: the evolution of elaborate care

459 After the emergence of family units, coevolutionary feedback-loops between parental and

460 offspring traits are expected to promote the evolution and diversification of parental care, and

461 thus to lead to the rapid consolidation of family life (Wolf, Brodie III, \& Moore, 1999; Kölliker,

462 Royle, \& Smiseth, 2012; Uller, 2012; Jarrett et al., 2017). For instance, the initial evolution of

463 parental provisioning may trigger evolutionary changes in other components of care as well as in

464 offspring traits, allowing parents to choose safer nest sites, but also increasing the competition

465 among offspring for parentally provided food. This increased sibling rivalry may, in turn, further

466 advance the evolution of parental provisioning, thereby closing the coevolutionary feedback-

467 loop between parental provisioning, the choice of safer nest sites, and sibling rivalry (Smiseth, 
468

469

470

471

472

473

474

475

476

477

478

479

480

481

482

483

484

485

486

487

488

Lennox, \& Moore, 2007; Gardner \& Smiseth, 2011). Such mutual reinforcement between parental and offspring traits has been predicted to promote a unidirectional trend from simple ancestral forms toward complex forms of family life by fostering an increasingly tight phenotypic integration of parental care and offspring development (Wilson, 1975; Gardner \& Smiseth, 2011; Kölliker et al., 2012; Uller, 2012; Royle et al., 2016). In the highly-derived family systems of altricial species, this phenotypic integration is advanced to such an extent that juveniles cannot survive without at least some care early in their life (Kölliker, 2007; Uller, 2012).

(b) An extended account I: the (changing) role of the neglected facets of family life

The increasingly tight integration of parental care into offspring development that evolves during the consolidation of family life could have a profound effect on the relative importance of the neglected facets of family life. For instance, the evolution of parental provisioning and the concomitant increased reliance of offspring on parentally provided food likely leads to a delayed onset of offspring foraging (cf. Gardner \& Smiseth, 2011), and should thus reduce the scope for competition between parents and their offspring. As a result, the impact of parent-offspring competition on family dynamics might steadily decline in the course of the consolidation of family life (Kramer et al., 2017). Similarly, siblings might be most likely to cooperate with each other as long as they are (still) largely independent of parental care. This is because an increased dependency on care is typically paralleled by increased sibling rivalry (Gardner \& Smiseth, 2011), and should thus decrease the levels of sibling cooperation (Frank, 1998, 2003). Finally, an increased offspring dependency is likely also accompanied by greater developmental constraints (cf. Maynard Smith et al., 1985) on the type of social behaviours that the immature juveniles can 
perform, suggesting that both sibling cooperation and offspring assistance might occur less frequently in altricial than in precocial species. Overall, these considerations indicate that parentoffspring competition, sibling cooperation, and offspring assistance might fulfil crucial roles in ancestral family systems, but could lose ground where the consolidation of family life promotes an increasingly tight phenotypic integration of parental care into offspring development.

While the role of parent-offspring competition, sibling cooperation, and offspring assistance in nuclear families thus far received little attention, their impact on the evolution of the extended families of cooperative breeders has been more thoroughly explored (e.g. Bourke \& Franks, 1995; Baglione et al., 2006; Koenig \& Dickinson, 2016; Sorato et al., 2016). Interestingly, all three facets play a prominent role in shaping these systems: parent-offspring competition can impede the evolution of cooperative breeding (Baglione et al., 2006; Sorato et al., 2016), siblings within breeding groups frequently cooperate with each other (e.g. during group foraging or in the defence against predation), and offspring assistance in the form of alloparental care (often called 'help') is the very foundation of cooperative breeding (Skutch, 1935; Cockburn, 1998; Koenig \& Dickinson, 2016). However, while these mechanisms usually involve juveniles in nuclear families, they typically involve adult offspring in cooperative breeders. Notably, the resurgence of these mechanisms in cooperative breeders after their demise during the consolidation of (nuclear) family life is in line with a key role of offspring dependency in determining their occurrence. Like juveniles in ancestral family systems, adult offspring in cooperative breeders are largely independent of parental care, a situation that not only promotes parent-offspring competition, but also shifts competition towards a global(population-wide) scale (cf. West et al., 2002), and thus prevents the high levels of sibling 
511 rivalry that usually reduce the likelihood that sibling cooperation and offspring assistance occur

512 (see above). The putatively similar role of these mechanisms in ancestral and cooperatively

513 breeding families suggests that the extensive literature on the evolution of cooperative breeding

514 could inform studies of the emergence of family life from a solitary state. In particular, the

515 distinction between a helper's decision to stay and its subsequent decision to provide

516 alloparental care (e.g. Ekman \& Tegelström, 1994; Griesser et al., 2017) could be applied to the

517 evolution of family units, and might then suggest that the initial formation of family units is not

518 necessarily (only) driven by the benefits of parental care (see also section IV.1).

519 (c) An extended account II: the rocky road to complex family systems

520 Far from being restricted to elucidating the role of the three neglected facets of family life, the

521 study of family interactions in precocial species can also shed light on other aspects of the

522 evolution of family living. For instance, it might help explaining why simple family life still abounds

523 across taxa (e.g. Tallamy \& Schaefer, 1997; Lin, Danforth, \& Wood, 2004; Filippi et al., 2009)

524 despite the expected trend towards complex family systems (Wilson, 1975; Gardner \&

525 Smiseth, 2011; Kölliker et al., 2012; Uller, 2012; Royle et al., 2016). In general terms, this

526 mismatch between theoretical expectations and empirical findings indicates that some as yet

527 unknown factors counteract the consolidation of family life and thus prevent an increase in social

528 complexity. We recently showed that long-term and transgenerational costs of parental loss

529 (such as an impaired development of juveniles) are not restricted to altricial family systems (e.g.

530 Harlow \& Suomi, 1971; Gonzalez et al., 2001; Fleming et al., 2002; Andres et al., 2013), but can

531 also occur in precocial species (Thesing et al., 2015). This finding suggests that the mortality rate 
532 of parents during family life could be one of the factors counteracting its consolidation. This is

533 because even though precocial juveniles can survive the early death of their parents, they will

534 still suffer (non-lethal) consequences of parental loss. Accordingly, high parental mortality rates

535 might not only increase the likelihood that these negative consequences arise; rather, they might

536 also select against the further consolidation of family life, since the concomitant deepened

537 integration of parental care into offspring development would increase the costs of parental loss.

538 Similarly, the consolidation of family life might be hindered where (variation in) the availability

539 of limited resources prevents parents from reliably provisioning their offspring. Such situations

540 could also select for the maintenance of alternative survival strategies among juveniles

541 (Kölliker, 2007; Kramer et al., 2015; Kramer \& Meunier, 2016a). We surmise that the reliability

542 of parental care - i.e. the likelihood that offspring indeed receive care once it has originated -

543 will prove crucial in determining whether a given family system evolves towards increasing

544 complexity (see also Capodeanu-Nägler et al., 2016).

Advanced family systems are typically caught in a parental trap that enforces the

546 maintenance of family life irrespective of its current adaptive value (Eberhard, 1975). By

547 contrast, less derived forms of family life can be lost over evolutionary times (Tallamy \&

548 Schaefer, 1997; Lin et al., 2004; Filippi et al., 2009). In the light of the above considerations, this

549 contrast indicates the existence of a threshold of social complexity that determines whether

550 family life is self-sustaining. Above this threshold, the phenotypic integration of parental care

551 into offspring development would be tight enough to render parental care obligatory for

552 offspring survival. Family life would then be beneficial to offspring irrespective of the external

553 conditions, and could thus hardly ever be lost. By contrast, the integration of parental care into 
554 offspring development below this threshold would be sufficiently limited to enable offspring

555 survival in the absence of the parents. In this situation, family life would remain facultative, and

556 the interplay between environmental conditions, life-history characteristics and the costs-benefit

557 ratio of all types of family interactions would determine whether family life is maintained at its

558 status quo, abandoned in favour of a solitary lifestyle, or propelled towards the threshold that

559 separates facultative from obligatory family systems. The existence of a similar threshold (or

560 point of no return) has been invoked to explain the transition from facultative to obligatory

561 eusociality (Wilson \& Hölldobler, 2005). With regard to the evolution of family life, such a

562 threshold would reconcile the current debate over the loss of parental care and family life (cf.

563 Trumbo, 2012), since it allows for the co-existence of stable as well as unstable family systems.

564 It would also leave scope for the theoretically expected unidirectional trend toward increasingly

565 complex family systems - namely if the prevailing conditions are favourable and stable enough

566 to promote an ever-increasing integration of parental and offspring traits.

\section{IV. IMPLICATIONS FOR SOCIAL EVOLUTION}

568 Throughout the history of life on earth, previously independent units (such as cells) have formed

569 social collectives (such as multicellular organisms) to cope with the challenges imposed by their

570 changing environment. Transitions from solitary to social life were the incipient steps in such

571 major transitions in evolution, and hence often had far-reaching repercussions on the diversity,

572 complexity, and hierarchical organization of life itself (Maynard Smith \& Szathmáry, 1995;

573 Bourke, 2011). Indeed, the quest for general mechanism driving such transitions has

574 prepossessed scientists ever since Charles R. Darwin (Darwin, 1859) first speculated on the 
575 evolution of eusocial societies (cf. Alexander, 1974; Krause \& Ruxton, 2002; Bourke, 2011).

576 Since then, the mechanisms driving transitions from simpler social systems to the highly 577 integrated and often permanent societies of cooperatively breeding vertebrates and eusocial 578 insects have been thoroughly explored (e.g. Wilson, 1971; Bourke \& Franks, 1995; Crozier \& 579 Pamilo, 1996; Koenig \& Dickinson, 2004, 2016). The evolutionary origin of the simpler social 580 systems themselves, however, has received less attention (Trumbo, 2012; Falk et al., 2014; van

581 Gestel \& Tarnita, 2017; Boomsma \& Gawne, 2017), and the mechanisms promoting the early 582 evolution of social life remain poorly understood. The emergence of family living exemplifies a transition from solitary to social life, and marks the origin of an (initially) simple social system. Moreover, it constitutes the initial step towards the major transition to eusociality (Maynard Smith \& Szathmáry, 1995; Bourke, 2011; Boomsma \& Gawne, 2017). Understanding the origin and consolidation of family life might thus help to shed light on processes that also shape (the early steps of) other evolutionary transitions (see also van Gestel \& Tarnita, 2017). In the

588 following part, we discuss how adopting a broad perspective on the evolution of family life could 589 provide general insights into the factors shaping social evolution.

590 (1) Pathways to group formation

591 Social interactions among juveniles likely have a crucial impact on the early evolution of family 592 units (see section III.1.b); yet their impact could go beyond the simple reinforcement of the 593 benefits of parental care. In particular, the benefits of such interactions might influence the initial 594 formation of family units, and could thus have implications for our understanding of the pathways to group formation. The transition to group-living is generally envisioned to follow 
either the semisocial or the subsocial pathway (Michener, 1969; Bourke, 2011). The semisocial pathway occurs when group formation results from the aggregation of individuals of the same generation, a process that, for instance, gave rise to the larval societies of sawflies and colonies of communally nesting halictid bees (Michener, 1969; Costa, 2006; Bourke, 2011). By contrast, the subsocial pathway occurs when group formation results from the association of parents with their offspring, an event that corresponds to the emergence of social interactions among the

602 family members (Queller, 2000; Bourke, 2011), and ultimately gave rise to the majority of advanced animal societies (Wheeler, 1928; Wilson, 1975; Bourke, 2011; Boomsma \&

604 Gawne, 2017). Interestingly, the potential role of sibling cooperation during early stages of the 605 evolution of family life (see section III.2.b) suggests that aggregations of juveniles might not only constitute an alternative (semisocial) pathway to group formation; rather, they could actually might subsequently give rise to families if parents extend already existing forms of pre-hatching

This scenario suggests that species might not only exhibit both the subsocial and the semisocial pathway to group formation during different stages of their life cycle (Costa, 2006); rather, they might follow the two pathways at different times in the course of their evolutionary history.

\section{4 (2) The rise and fall of cooperation and conflict}

615 In the course of major evolutionary transitions, cooperation typically spreads among lower-level 
617 conflicts between them (Bourke, 2011). The evolution of family life shows evidence for both

618 processes: parental care, a hallmark cooperative trait (Hamilton, 1964; Smiseth et al., 2012),

619 greatly diversifies during the evolution of complex family systems. Conversely, the initially

620 prevailing direct competition between parents and offspring might be progressively suppressed

621 (Kramer et al., 2017). However, the evolutionary dynamics shaping family living also indicate that

622 not all forms of cooperation might be favoured and not all conflicts equally suppressed during its

623 consolidation. For instance, cooperation among juvenile siblings might occur frequently in

624 facultative family systems, but is arguably rare in advanced systems with obligatory family life

625 (Roulin \& Dreiss, 2012; Kramer et al., 2015). Conversely, sibling rivalry and parent-offspring

626 conflict (sensu Trivers, 1974) typically increase during the evolution of complex family systems

627 (Gardner \& Smiseth, 2011). These findings suggest that some conflicts that are characteristic of

628 later stages in an evolutionary transition might arise from dynamics that shaped earlier stages of

629 that transition. In more general terms, they indicate that the increase in cooperation and the

630 suppression of conflicts might be overall trends that need to hold true neither for all types of

631 cooperation and conflict, nor for all stages of a transition. Notably, social systems might evolve

632 towards a major transition even if a specific form of cooperation [such as sibling cooperation] is

633 lost - namely if its benefits are offset by the benefits of a simultaneous increase in another form

634 of cooperation [such as parental care] and/or the reduction in the costs of some form of conflict

635 [such as parent-offspring competition]. 


\section{6 (3) The consolidation of social life}

637 The various stages of a major transition broadly fall into two categories describing the initial 638 formation of collectives (such as groups) out of formerly independent particles (such as

639 individuals) on the one hand, and the subsequent transformation of these collectives on the 640 other hand (Bourke, 2011). This transformational phase entails the transfer of key (e.g. 641 metabolic or reproductive) functions from the particle to the collective level (Maynard Smith \&

642 Szathmáry, 1995; Bourke, 2011), and hence exhibits a striking resemblance to the consolidation

643 of family life. In both cases, an increasingly tight phenotypic integration ties the fate of single 644 particles [offspring] closer and closer to the fate of the collective [family], eventually resulting in 645 obligatory social life - that is the inability of particles [offspring] to survive alone. This 646 resemblance suggests that the reliability with which particles can derive benefits from the 647 collective might have a crucial role in the transformational phase that corresponds to the role of 648 the reliability of parental care in the consolidation of family life (see section III.2.c). For instance, 649 the likelihood of a costly collapse of a facultative collective (i.e. the likelihood of 'collective 650 mortality') might influence whether the phenotypic integration among its constituent particles 651 proceeds, and could thus ultimately determine whether the collective becomes obligatory for 652 particle-survival. Like the shift from facultative to obligatory family life, the shift from facultative 653 to obligatory collectives could occur when environmental conditions and life-history 654 characteristics of the particles allow for the breaching of a threshold of social complexity (see 655 section III.2.b). Interestingly, the increasing phenotypic integration among the particles 656 underlying this shift might also be paralleled by a shift from particle to collective-level selection 657 (Okasha, 2005; Shelton \& Michod, 2010). This change in the most relevant level of selection 
658 could in turn determine whether kin selection or multilevel selection approaches best describe

659 the underlying evolutionary process (Kramer \& Meunier, 2016b; Okasha, 2016). The different

660 stages of the evolution of family life offer rich opportunities to investigate these possibilities.

661 Exploring the intricacies of family life might thus be a good starting point to advance our

662 understanding of the major transitions and the theoretical framework of sociobiology.

\section{VI. CONCLUSIONS}

664 (1) Over the last decades, the intricacies of family interactions received theoretical and empirical

665 scrutiny in a plethora of studies that focused on parental care and its associated family

666 interactions (such as those arising from sibling rivalry and parent-offspring conflict), and

667 investigated these phenomena in altricial vertebrates and eusocial insects. This historical bias

668 bears on the often-substantial fitness effects of these phenomena in derived family systems.

669 However, it has led to a neglect of mechanisms that might be particularly important in shaping

670 the social life in less-derived family systems. Consequently, a coherent framework for the study

671 of social interactions and fitness effects of family life is currently missing, and our understanding

672 of the (early) evolution of family life remains limited.

673 (2) Here, we argued that the explicit consideration of thus far neglected facets of family life - and

674 their study across the whole taxonomical diversity of family systems - is crucial to shed light on

675 the mechanisms driving the evolution of social life in family groups. In particular, we illustrated

676 that the strong focus on parental care in advanced social systems has fostered the neglect of

677 three facets of family life: sibling cooperation, parent-offspring competition, and offspring 
678

679

680

681

682

683

684

685

686

687

688

689

690

691

692

693

694

695

696

697

698

assistance. We suggested that the impact of these facets is often - and especially in derived family systems - concealed by the fitness effects of parental care.

(3) We showed how accounting for these overlooked facets - and their changing role in the course of evolution - is nevertheless crucial, and could improve our understanding of the evolutionary emergence and consolidation of family life. Specifically, we highlight that both sibling cooperation and offspring assistance could promote the evolutionary emergence of family life by, respectively, augmenting the benefits and offsetting some of the costs of parental care. Conversely, we suggest that parent-offspring competition might impede the evolution of family life by reducing the net benefits of care. We argue that all three thus far neglected facets have a greater impact where offspring are largely independent of (and thus do not compete for) parental care - a scenario that prevailed during the early evolution of family life, and is prevalent among contemporary precocial species and in adult offspring of cooperative breeders.

(4) We show that the study of family interactions in (precocial) species featuring non-derived forms of family life is not restricted to elucidating the role of sibling cooperation, parent-offspring competition, and offspring assistance; rather it can also shed light on factors - such as the reliability of the benefits of parental care - that can affect the benefits of a (further) consolidation of family life, and thus promote or hamper the evolution of complex animal societies.

(5) Finally, we discuss how diachronic perspective on the evolution of family living could provide novel insights into the mechanisms driving social evolution. In particular, we suggest that (subsocial) family life can evolve secondarily from semisocial aggregations of juveniles that delay dispersal to reap the benefits of sibling cooperation. We argue that the role of the reliability of 
699 the benefits of parental care in the consolidation of family life can be generalized, which would

700 suggest a key role of the reliability of 'collective' benefits in the consolidation of social life.

701 (6) Overall, we aimed at providing a general perspective on the evolution of family life that

702 accounts for all types of family interaction across the whole taxonomical diversity of family

703 systems. Recent advances in the study of parental care stress its multifaceted nature (e.g.

704 Gardner \& Smiseth, 2011; Royle et al., 2016; Andrews, Kruuk, \& Smiseth, 2017); we hope that

705 our perspective on the intricacies of family life complements this fruitful trend by raising

706 awareness for the multifaceted nature of social life in family groups. The further development of

707 this perspective hinges on studies that investigate family life in species with non-derived

708 (facultative) forms of family life. Many allegedly 'primitively social' insects (see Tallamy \&

709 Wood, 1986; Costa, 2006; Trumbo, 2012; Wong et al., 2013 for reviews) offer unprecedented

710 opportunities to study the origin and maintenance of early forms of parental care and family life

711 (Smiseth et al. 2003b; Kölliker 2007; Trumbo 2012). We believe that their resemblance to

712 ancestral family systems, and the great diversity of family interactions across species, could well

713 render them prime models of social evolution.

\section{VII. ACKNOWLEDGEMENTS}

715 The authors thank Maximilian Körner for his comments on a previous version of this manuscript.

716 JK was supported by a grant from the University of Zürich (Forschungskredit of the University of

717 Zurich, grant no. [FK-17-111]). 


\section{REFERENCES}

719

720

721

722

723

724

725

726

727

728

729

730

731

732

733

734

735

736

737

738

739

AleXANDER, R.D. (1974) The evolution of social behavior. Annual Review of Ecology and Systematics 5, 325-383.

Alonso-Alvarez, C. \& Velando, A. (2012) Benefits and costs of parental care. In The evolution of parental care (eds N.J. ROYLE, P.T. SMISETH \& M. KÖLLIKER), pp. 40-61. Oxford University Press, Oxford.

ANDERSON, D.J. \& RICKLEFS, R.E. (1995) Evidence of kin-selected tolerance by nestlings in a siblicidal bird. Behavioral Ecology and Sociobiology 37, 163-168.

Andres, D., Clutton-Brock, T.H., KruUk, L.E., Pemberton, J.M., Stopher, K. V \& Ruckstuhl, K.E. (2013) Sex differences in the consequences of maternal loss in a long-lived mammal, the red deer (Cervus elaphus). Behavioral Ecology and Sociobiology 67, 1249-1258.

ANDREWS, C.P., KRUUK, L.E.B. \& SMISETH, P.T. (2017) Evolution of elaborate parental care: phenotypic and genetic correlations between parent and offspring traits. Behavioral Ecology 28, 39-48.

Badyaev, A. V \& Uller, T. (2009) Parental Effects in Ecology and Evolution : Mechanisms, Processes and Implications. Philosophical Transactions of the Royal Society B: Biological Sciences 364, 1169-1177.

Baglione, V., CAnestrari, D., Marcos, J.M. \& Ekman, J. (2006) Experimentally increased food resources in the natal territory promote offspring philopatry and helping in cooperatively breeding carrion crows. Proceedings of the Royal Society B: Biological Sciences 273, 15291535.

BARRÉ, H. (1984) Metabolic and insulative changes in winter- and summer-acclimatized King 
Penguin chicks. Journal of Comparative Physiology B 154, 317-324.

741

742

743

744

745

746

747

748

749

750

751

752

753

754

755

756

757

758

759

760

761

BATESON, P. (1994) The dynamics of parent-offspring relationships in mammals. Trends in Ecology \& Evolution 9, 399-403.

BELL, M.B. V (2007) Cooperative begging in banded mongoose pups. Current Biology 17, 717721.

BiedermanN, P.H.W. \& TABORSKY, M. (2011) Larval helpers and age polyethism in ambrosia beetles. Proceedings of the National Academy of Sciences of the United States of America $108,17064-17069$.

BONSALL, M.B. \& KLUG, H. (2011a) The evolution of parental care in stochastic environments. Journal of Evolutionary Biology 24, 645-655.

BONSALL, M.B. \& KLUG, H. (2011b) Effects of among-offspring relatedness on the origins and evolution of parental care and filial cannibalism. Journal of Evolutionary Biology 24, 13351350.

BoOMSMA, J.J. \& GAWNE, R. (2017) Superorganismality and caste differentiation as points of no return: how the major evolutionary transitions were lost in translation. Biological Reviews in press.

BøRGESEN, L.W. (1989) A New Aspect of the Role of Larvae in the Pharaoh's Ant Society (Monomorium Pharaonis (L .) - Formicidae, Myrmicinae): Producer of Fecundity-Increasing Substances to the Queen. Insectes Sociaux 36, 313-327.

BØRGESEN, L.W. \& JENSEN, P. V (1995) Influence of larvae and workers on egg production of queens of the pharaoh's ant, Monomorium pharaonis (L.). Insectes Sociaux 42, 103-112. 
nestling interactions in a Mississippi kite (Ictinia mississippiensis) nest. Journal of Raptor Research 27, 16-20.

Botterill-James, T., Halliwell, B., Cooper-Scott, E., Uller, T., Wapstra, E. \& While, G.M. (2016) Habitat Structure Influences Parent-Offspring Association in a Social Lizard. Frontiers in Ecology and Evolution 4, 1-10.

BouRKe, A.F.G. (2011) Principles of social evolution. Oxford University Press, Oxford.

Bourke, A.F.G. \& FranKs, N.R. (1995) Social Evolution in Ants. Princeton University Press, Princeton.

BOWERS, E.K., SAKALUK, S.K. \& THOMPSON, C.F. (2013) Sibling cooperation influences the age of nest leaving in an altricial bird. The American Naturalist 181, 775-786.

Bulmer, E., Celis, P. \& GIL, D. (2008) Parent-absent begging: Evidence for sibling honesty and cooperation in the spotless starling (Sturnus unicolor). Behavioral Ecology 19, 279-284.

Capodeanu-Nägler, A., Keppner, E.M., Vogel, H., Ayasse, M., Eggert, A.-K., Sakaluk, S.K. \& Steiger, S. (2016) From facultative to obligatory parental care: Interspecific variation in offspring dependency on post-hatching care in burying beetles. Scientific Reports 6, 29323.

CARTER, G.G. \& WILKINSON, G.S. (2013) Food sharing in vampire bats: reciprocal help predicts donations more than relatedness or harassment. Proceedings of the Royal Society B: Biological Sciences 280, 20122573-20122573.

Clutton-Brock, T.H. (1991) The evolution of parental care. Princeton University Press, Princeton.

COCKBURN, A. (1998) Evolution of helping behavior in cooperatively breeding birds. Annual Review of Ecology and Systematics 29, 141-177.

COMINS, H.N., HAMILTON, W.D. \& MAY, R.M. (1980) Evolutionarily stable dispersal strategies. 
Journal of Theoretical Biology 82, 205-230.

CostA, J.T. (2006) The Other Insect Societies. Harvard University Press, Cambridge.

COTE, J., CLOBERT, J. \& FITZE, P.S. (2007) Mother-offspring competition promotes colonization success. Proceedings of the National Academy of Sciences of the United States of America 104, 9703-9708.

COVAS, R. \& GRIESSER, M. (2007) Life history and the evolution of family living in birds. Proceedings of the Royal Society of London, Series B 274, 1349-1357.

Cremer, S., Armitage, S.A.O. \& Schmid-Hempel, P. (2007) Social Immunity. Current Biology 17, 693-702.

Crozier, R.H. \& PAMILO, P. (1996) Evolution of Social Insect Colonies: Sex Allocation and Kin Selection. Oxford University Press, Oxford. neuropeptide F in a transition to parental care. Biology Letters 12, 20160158.

DARWIN, C.R. (1859) On the Origin of Species by Means of Natural Selection. John Murray, London.

DARWIN, C.R. (1871) The Descent of Man and Selection in Relation to Sex. D. Appleton and Company, New York.

DICKINSON, J.L. \& McGowAN, A. (2005) Winter resource wealth drives delayed dispersal and family-group living in western bluebirds. Proceedings of the Royal Society B: Biological Sciences 272, 2423-2428. 
806

807

808

809

810

811

812

813

814

815

816

817

818

819

820

821

822

823

824

825

826

827

DOBLER, R. \& KÖLLIKER, M. (2011) Influence of weight asymmetry and kinship on siblicidal and cannibalistic behaviour in earwigs. Animal Behaviour 82, 667-672.

Dreiss, A.N., LAHLAH, N. \& Roulin, A. (2010) How siblings adjust sib-sib communication and begging signals to each other. Animal Behaviour 80, 1049-1055.

Drobniak, S.M., Wagner, G., Mouroca, E. \& Griesser, M. (2015) Family living: an overlooked but pivotal social system to understand the evolution of cooperative breeding. Behavioral Ecology 26, 805-811.

Duarte, A., Cotter, S.C., Reavey, C.E., Ward, R.J.S., De Gasperin, O. \& Kilner, R.M. (2016) Social immunity of the family: parental contributions to a public good modulated by brood size. Evolutionary Ecology 30, 123-135.

Dussutour, A. \& SIMPSON, S.J. (2009) Communal Nutrition in Ants. Current Biology 19, 740-744.

Eberhard, W.G. (1975) The Ecology and Behavior of a Subsocial Pentatomid Bug and Two Scelionid Wasps: Strategy and Counterstrategy in a Host and Its Parasites. Smithsonian Contributions to Zoology 205, 1-39.

Eggert, A.-K., ReInKIng, M. \& MülLER, J.K. (1998) Parental care improves offspring survival and growth in burying beetles. Animal Behaviour 55, 97-107.

Eggleton, P. (2011) An Introduction to Termites: Biology, Taxonomy and Functional Morphology. In Biology of Termites: A Modern Synthesis (eds D.E. BIGNELL, Y. RoISIN \& N. Lo), pp. 1-26. Springer.

EkMAN, J. \& TEgelSTRÖM, H. (1994) Offspring retention in the Siberian jay (Perisoreus infaustus): the prolonged brood care hypothesis. Behavioral Ecology 5, 245-253.

EMLEN, S.T. (1994) Benefits, constrainsts and the evolution of the family. Trends in Ecology \& 
Evolution 9, 282-285.

EmLen, S.T. (1995) An evolutionary theory of the family. Proceedings of the National Academy of Sciences of the United States of America 92, 8092-8099.

EvANS, T.A. (1998) Offspring recognition by mother crab spiders with extreme maternal care. Proceedings of the Royal Society B: Biological Sciences 265, 129-134.

FALK, J., WONG, J.W.Y., KÖLLIKER, M. \& MeUnIER, J. (2014) Sibling cooperation in earwig families provides insights into the early evolution of social life. The American Naturalist 183, 547557.

FELLOWES, M.D.E. (1998) Do non-social insects get the (kin) recognition they deserve? Ecological Entomology 23, 223-227.

FilipPI, L., BABA, N., INAdOMI, K., YANAGI, T., HiRonaka, M. \& NomakuchI, S. (2009) Pre- and posthatch trophic egg production in the subsocial burrower bug, Canthophorus niveimarginatus (Heteroptera: Cydnidae). Naturwissenschaften 96, 201-211.

Fleming, A.S., Kraemer, G.W., Gonzalez, A., Lovic, V., Rees, S. \& Melo, A. (2002) Mothering begets mothering: the transmission of behavior and its neurobiology across generations. Pharmacology Biochemistry and Behavior 73, 61-75.

FORBES, L.S. (2007) Sibling Symbiosis in Nestling Birds. The Auk 124, 1-10.

Frank, S.A. (1998) Foundations of social evolution. Princeton University Press, Princeton.

Frank, S.A. (2003) Prespective: Repression of Competition and the Evolution of Cooperation. Evolution 57, 693.

Le Galliard, J.-F., FerriÈre, R. \& Clobert, J. (2003) Mother-offspring interactions affect natal dispersal in a lizard. Proceedings of the Royal Society B: Biological Sciences 270, 1163- 
1169.

GARDNER, A. \& SMISETH, P.T. (2011) Evolution of parental care driven by mutual reinforcement of parental food provisioning and sibling competition. Proceedings of the Royal Society B: Biological Sciences 278, 196-203.

VAN GESTEL, J. \& TARNITA, C.E. (2017) On the origin of biological construction, with a focus on multicellularity. Proceedings of the National Academy of Sciences 114, 11018-11026.

GonZAlez, A., Lovic, V., WARD, G.R., WainWRight, P.E. \& Fleming, A.S. (2001) Intergenerational effects of complete maternal deprivation and replacement stimulation on maternal behavior and emotionality in female rats. Developmental Psychobiology 38, 11-32.

Griesser, M., Drobniak, S.M., Nakagawa, S. \& Botero, C.A. (2017) Family living sets the stage for cooperative breeding and ecological resilience in birds. PLOS Biology 15, e2000483.

Gross, M.R. \& Clutton-Brock, T.H. (2005) The Evolution of Parental Care. In The Quarterly Review of Biology p. .

HAMILTON, W.D. (1964) The genetical evolution of social behaviour. I. Journal of Theoretical Biology 7, 1-16.

HAMILTON, W.D. \& MAY, R.M. (1977) Dispersal in stable habitats. Nature 269, 578-581.

Harlow, H.F. \& SUOMI, S.J. (1971) Social Recovery by Isolation-Reared Monkeys. Proceedings of the National Academy of Sciences of the United States of America 68, 1534-1538.

HölLdobleR, B. \& Wilson, E.O. (1990) The Ants. Harvard University Press, Harvard.

Howard, K.J. \& Thorne, B.L. (2011) Eusocial Evolution in Termites and Hymenoptera. In Biology of Termites: A Modern Synthesis (eds D.E. BIGNELL, Y. RoISIN \& N. Lo), pp. 97-132. Springer. HUNT, J.H. (1984) Adult nourishment during larval provisioning in a primitively Eusocial wasp, 
Polistes metricus Say. Insectes Sociaux 31, 452-460.

JarRett, B.J.M., Schrader, M., Rebar, D., Houslay, T.M. \& Kilner, R.M. (2017) Cooperative interactions within the family enhance the capacity for evolutionary change in body size. Nature Ecology \& Evolution 1, 178.

JOHNSTONE, R.A. (2004) Begging and Sibling Competition: How Should Offspring Respond to Their Rivals ? The American Naturalist 163, 388-406.

Johnstone, R.A. \& Roulin, A. (2003) Sibling negotiation. Behavioral Ecology 14, 780-786.

JONES, T.C. \& PARKER, P.G. (2002) Delayed juvenile dispersal benefits both mother and offspring in the cooperative spider Anelosimus studiosus (Araneae: Theridiidae). Behavioral Ecology $13,142-148$.

KILNER, R.M. \& HINDE, C.A. (2012) Parent-offspring conflict. In The Evolution of Parental Care (eds N.J. ROYLE, P.T. SMISETH \& M. KÖLLIKER), pp. 119-132. Oxford University Press, Oxford.

KLUG, H., Alonso, S.H. \& Bonsall, M.B. (2012) Theoretical foundations of parental care. In The Evolution of Parental Care (eds N. RoyLE, M. KöLLIKER \& P.T. SMISETH), pp. 21-39. Oxford University Press, Oxford.

KLUG, H. \& BONSALL, M.B. (2010) Life history and the evolution of parental care. Evolution 64, 823-835.

KLUG, H. \& BONSALL, M.B. (2014) What are the benefits of parental care? The importance of parental effects on developmental rate. Ecology and Evolution 4, 2330-2351.

KOENIG, W.D. \& DICKINSON, J.L. (2004) Ecology and evolution of cooperative breeding in birds. Cambridge University Press, Cambridge.

KOENIG, W.D. \& DICKINSON, J.L. (eds) (2016) Cooperative Breeding in Vertebrates: Studies of 
Ecology, Evolution, and Behavior. Cambridge University Press, Cambridge.

895

896

897

898

899

900

901

902

903

904

905

906

907

908

909

910

911

912

913

914

915

KoENIG, W.D. \& WALTERS, E.L. (2015) Temporal variability and cooperative breeding: testing the bet-hedging hypothesis in the acorn woodpecker. Proceedings of the Royal Society B 282, 20151742.

KöLLIKER, M. (2007) Benefits and costs of earwig (Forficula auricularia) family life. Behavioral Ecology and Sociobiology 61, 1489-1497.

Kölliker, M., Boos, S., Wong, J.W.Y., Röluin, L., Stucki, D., Raveh, S., Wu, M. \& Meunier, J. (2015) Parent-offspring conflict and the genetic trade-offs shaping parental investment. Nature Communications 6, 6850 .

KÖLLIKER, M., RoYLE, N.J. \& SMISETH, P.T. (2012) Parent-offspring co-adaptation. In The Evolution of Parental Care (eds N.J. ROYLE, P.T. SMISETH \& M. KÖLLIKER), pp. 285-303. Oxford University Press, Oxford.

Kramer, J., Körner, M., Diehl, J.M., Scheiner, C., YüKSel-Dadak, A., Christl, T., KohlmeieR, P. \& MEUnIER, J. (2017) When earwig mothers do not care to share: Parent-offspring competition and the evolution of family life. Functional Ecology 31, 2098-2107.

Kramer, J. \& Meunier, J. (2016a) Maternal condition determines offspring behavior toward family members in the European earwig. Behavioral Ecology 27, 494-500.

Kramer, J. \& Meunier, J. (2016b) Kin and multilevel selection in social evolution: a never-ending controversy? F1000Research 5, 776.

Kramer, J., Thesing, J. \& Meunier, J. (2015) Negative association between parental care and sibling cooperation in earwigs: a new perspective on the early evolution of family life? Journal of Evolutionary Biology 28, 1299-1308. 
916

917

918

919

920

921

922

923

924

925

926

927

928

929

930

931

932

933

934

935

936

937

KrAUSE, J. \& Ruxton, G.D. (2002) Living in groups. Oxford University Press, Oxford.

LACK, D. (1968) Ecological adaptations for breeding in birds. Methuen \& Co., London, UK.

LÉnA, J.P., Clobert, J., de Fraipont, M., Lecomte, J. \& Guyot, G. (1998) The relative influence of density and kinship on dispersal in the common lizard. Behavioral Ecology 9, 500-507.

LESSELLS, C.M. (2012) Sexual conflict. In The Evolution of Parental Care (eds N.J. RoyLE, P.T. SMISETH \& M. KöLLIKER), pp. 150-170. Oxford University Press, Oxford.

LIN, C.-P., DANFORTH, B.N. \& WOOD, T.K. (2004) Molecular Phylogenetics and Evolution of Maternal Care in Membracine Treehoppers. Systematic Biology 53, 400-421.

LION, S. \& VAN BAALEN, M. (2007) From Infanticide to Parental Care: Why Spatial Structure Can Help Adults Be Good Parents. The American Naturalist 170, E26-E46.

Madden, J.R., Kunc, H.P., English, S., MAnser, M.B. \& Clutton-Brock, T.H. (2009) Calling in the gap: competition or cooperation in littermates' begging behaviour? Proceedings of the Royal Society B: Biological Sciences 276, 1255-1262.

MARTI, C.D. (1989) Food sharing by sibling Common Barn-owls. The Wilson Bulletin 101, 132134.

MAtheVon, N. \& ChARRIer, I. (2004) Parent-offspring conflict and the coordination of siblings in gulls. Proceedings of the Royal Society B: Biological Sciences 271, S145-S147.

Maynard Smith, J., Burian, R., Kauffman, S., Alberch, P., Cambell, J., Goodwin, B., Lande, R., Raup, D. \& WolPERT, L. (1985) Developmental Constraints and Evolution. The Quarterly Review of Biology 60, 265-287.

MaynaRd SMith, J. \& SzATHMÁRY, E. (1995) The Major Transitions in Evolution. Oxford University Press, New York. 
938

939

940

941

942

943

944

945

946

947

948

949

950

951

952

953

954

955

956

957

958

959

Meunier, J. (2015) Social immunity and the evolution of group living in insects. Philosophical

Transactions of the Royal Society B: Biological Sciences 370, $20140102-20140102$.

MEUNIER, J. \& KöLLIKER, M. (2012) When it is costly to have a caring mother: food limitation

erases the benefits of parental care in earwigs. Biology Letters 8, 547-550.

Michener, C.D. (1969) Comparative Social Behavior of Bees. Annual Review of Entomology 14, 299-342.

Mock, D.W. \& PARKER, G.A. (1997) The evolution of sibling rivalry. Oxford University Press, Oxford.

ОкаSнA, S. (2005) Multilevel selection and the Major Transitions in Evolution. Philosophy of Science 72, 1013-1025.

OKASHA, S. (2016) The Relation between Kin and Multilevel Selection: An Approach Using Causal Graphs. The British Journal for the Philosophy of Science 67, 435-470.

Palmer, W.J., Duarte, A., Schrader, M., Day, J.P., Kilner, R. \& Jiggins, F.M. (2016) A gene associated with social immunity in the burying beetle Nicrophorus vespilloides. Proceedings of the Royal Society B: Biological Sciences 283, 20152733.

Parker, D.J., Cunningham, C.B., Walling, C.A., Stamper, C.E., Head, M.L., Roy-Zokan, E.M., MCKINNEY, E.C., RITCHIE, M.G. \& MoORE, A.J. (2015) Transcriptomes of parents identify parenting strategies and sexual conflict in a subsocial beetle. Nature Communications 6, 8449.

PARKer, G.A., Royle, N.J. \& HARTLEY, I.R. (2002) Intrafamilial conflict and parental investment: a synthesis. Philosophical Transactions of the Royal Society B: Biological Sciences 357, 295307. 
960

961

962

963

964

965

966

967

968

969

970

971

972

973

974

975

976

977

978

979

980

981

QUELLER, D.C. (2000) Relatedness and the fraternal major transitions. Philosophical Transactions of the Royal Society B: Biological Sciences 355, 1647-1655.

RoulIN, A. (2002) The sibling negotiation hypothesis. In The evolution of begging: competition, cooperation and communication (eds J. WRIGHT \& M.L. LEONARD), pp. 107-127. Springer.

Roulin, A. \& DREISS, A.N. (2012) Sibling competition and cooperation over parental care. In The Evolution of Parental Care (eds N.J. RoYLe, P.T. SMISETH \& M. KÖLLIKER), pp. 133-149. Oxford University Press, Oxford.

Royle, N.J., Alonzo, S.H. \& Moore, A.J. (2016) Co-evolution, conflict and complexity: what have we learned about the evolution of parental care behaviours? Current Opinion in Behavioral Sciences 12, 30-36.

Royle, N.J., HaRTLEy, I.R. \& PARKer, G.A. (2004) Parental investment and family dynamics: Interactions between theory and empirical tests. Population Ecology 46, 231-241.

ROYLE, N.J., SMISETH, P.T. \& KöLLIKER, M. (2012a) The evolution of parental care: summary, conclusions, and implications. In The Evolution of Parental Care (eds N.J. ROYLE, P.T. SMISETH \& M. KÖLLIKER), pp. 327-345. Oxford University Press, Oxford.

Royle, N.J., SMiseth, P.T. \& Kölliker, M. (eds) (2012b) The Evolution of Parental Care. Oxford University Press, Oxford.

SAlomon, M., SCHneIder, J. \& LUbin, Y. (2005) Maternal investment in a spider with suicidal maternal care, Stegodyphus lineatus (Araneae, Eresidae). Oikos 109, 614-622.

SChrader, M., JARRett, B.J.M. \& Kilner, R.M. (2015a) Parental care masks a density-dependent shift from cooperation to competition among burying beetle larvae. Evolution 69, 10771084. 
982

983

984

985

986

987

988

989

990

991

992

993

994

995

996

997

998

999

1000

1001

1002

1003

Schrader, M., Schrader, M., JARRett, B.J.M. \& Kilner, R.M. (2015b) Using Experimental Evolution to Study Adaptations for Life within the Family. The American Naturalist 185, 610-619.

SChultner, E., Oettler, J. \& Helanterä, H. (2017) The role of brood in Hymenopteran societies. The Quarterly Review of Biology 92, 40.

SCOTT, M.P. \& GLADSTEIN, D.S. (1993) Calculating males? An empirical and theoretical examination of the duration of paternal care in burying beetles. Evolutionary Ecology 7, 362-378.

SHeLton, D.E. \& MiCHOD, R.E. (2010) Philosophical foundations for the hierarchy of life. Biology \& Philosophy 25, 391-403.

SKUTCH, A.F. (1935) Helpers at the nest. The Auk 52, 257-273.

Smale, L., Holekampt, K.E., Weldele, M., Frank, L.G. \& Glickmanj, S.E. (1995) Competition and cooperation between litter-mates in the spotted hyaena, Crocuta crocuta. Animal Behaviour 50, 671-682.

SMISETH, P.T., DARWELL, C.T. \& MoORE, A.J. (2003) Partial begging: an empirical model for the early evolution of offspring signalling. Proceedings of the Royal Society B: Biological Sciences 270, 1773-1777.

SMISETH, P.T., KÖLLIKER, M. \& ROYLE, N.J. (2012) What is parental care? In The Evolution of Parental Care (eds N.J. RoYLE, P.T. SMISETH \& M. KöLLIKER), pp. 1-14. Oxford University Press, Oxford.

SMiseth, P.T., Lennox, L. \& Moore, A.J. (2007) Interaction between parental care and sibling competition: parents enhance offspring growth and exacerbate sibling competition. Evolution 61, 2331-2339.

Sorato, E., GrifFith, S.C. \& RusSell, A.F. (2016) The price of associating with breeders in the 
1004

1005

1006

1007

1008

1009

1010

1011

1012

1013

1014

1015

1016

1017

1018

1019

1020

1021

1022

1023

1024

1025

cooperatively breeding chestnut-crowned babbler: foraging constraints, survival and sociality. Journal of Animal Ecology 85, 1340-1351.

Tallamy, D.W. (1984) Insect Parental Care. BioScience 34, 20-24.

TALLAMY, D.W. \& SCHAEFER, C. (1997) Maternal care in the Hemiptera: ancestry, alternatives, and current adaptive value. In The Evolution of Social Behavior in Insects and Arachnids (eds J.C. ChOE \& B. CRESPI), pp. 94-115. Cambridge University Press, Cambridge.

Tallamy, D.W. \& Wood, T.K. (1986) Convergence Patterns in Subsocial Insects. Annual Review of Entomology 31, 369-390.

Thesing, J., Kramer, J., Koch, L.K. \& MeUnieR, J. (2015) Short-term benefits, but transgenerational costs of maternal loss in an insect with facultative maternal care. Proceedings of the Royal Society B: Biological Sciences 282, 20151617.

TRIVERS, R.L. (1972) Parental investment and sexual selection. In Sexual selection and the descent of man, 1871-1971 (ed B. CAMPBELL), pp. 136-179. Heinemann Educational Books, Chicago.

TRIVERS, R.L. (1974) Parent-offspring conflict. American Zoologist 14, 249-264.

TRumbo, S.T. (2012) Patterns of parental care in invertebrates. In The Evolution of Parental Care (eds N.J. RoYLe, P.T. SMISETH \& M. KöLLIKER), pp. 81-100. Oxford University Press, Oxford.

UlLER, T. (2012) Parental effects in development and evolution. In The Evolution of Parental Care (eds N.J. RoYLE, P.T. SMISETH \& M. KÖLLIKER), pp. 247-266. Oxford University Press, Oxford.

Webb, J.N., Székely, T., Houston, A.I. \& McNamara, J.M. (2002) A theoretical analysis of the energetic costs and consequences of parental care decisions. Philosophical Transactions of the Royal Society B: Biological Sciences 357, 331-340.

West, S.A., Murray, M.G., Machado, C.A., Griffin, A.S. \& Herre, E.A. (2001) Testing Hamilton's 
rule with competition between relatives. Nature 409, 510-513.

1027 WeSt, S.A., PEN, I. \& GRIFFIn, A.S. (2002) Cooperation and competition between relatives. Science

1028

1029

1030

1031

1032

1033

1034

1035

1036

1037

1038

1039

1040

1041

1042

1043

1044

1045

1046

1047

(New York, N.Y.) 296, 72-75.

WheELER, W.M. (1918) A Study of Some Ant Larvæ, with a Consideration of the Origin and Meaning of the Social Habit among Insects. Proceedings of the American Philosophical Society $57,293-343$.

WheELER, W.M. (1928) The Social Insects: Their Origin and Evolution. Harcourt, Brace, New York.

WILKINSON, G.S. (1984) Reciprocal food sharing in the vampire bat. Nature 308, 181-184.

WILLIAMS, G.C. (1966) Adaptation and Natural Selection: A Critique of Some Current Evolutionary Thought. Princeton University Press, Princeton.

WILSON, E.O. (1971) The Insect Societies. Harvard University Press, Harvard.

WILSON, E.O. (1975) Sociobiology: The new synthesis. Harvard University Press, Cambridge.

WiLSON, E.O. \& HöLLDOBLER, B. (2005) Eusociality: Origin and consequences. Proceedings of the National Academy of Sciences of the United States of America 102, 13367-13371.

Wolf, J.B., BRodiE III, E.D. \& MOORE, A.J. (1999) Interacting Phenotypes and the Evolutionary Process. II. Selection Resulting from Social Interactions. The American Naturalist 153, 254266.

WONG, J.W.Y. \& KöLLIKER, M. (2012) The effect of female condition on maternal care in the European earwig. Ethology 118, 450-459.

WONG, J.W.Y., MEUNIER, J. \& KÖLLIKER, M. (2013) The evolution of parental care in insects: the roles of ecology, life history and the social environment. Ecological Entomology 38, 123137. 
1048 YIP, E.C. \& RAYOR, L.S. (2013) The influence of siblings on body condition in a social spider: is prey

1049 sharing cooperation or competition? Animal Behaviour 85, 1161-1168. Elsevier Ltd.

1050 YIP, E.C. \& RAYOR, L.S. (2014) Maternal care and subsocial behaviour in spiders. Biological

$1051 \quad$ Reviews 89, 427-449.

1052 ZINK, A.G. (2003) Quantifying the costs and benefits of parental care in female treehoppers.

1053 Behavioral Ecology 14, 687-693. 